\title{
Reconhecimento entre estados Sobre a base moral das relações internacionais
}

\author{
Recognition between States
}

On the moral substrate of international relations

Axel Honneth*

Resumo: Contrariamente à percepção cotidiana de que os atores estatais têm como objetivo de suas ações o respeito e o reconhecimento da comunidade por eles representada, prevalece na moderna teoria predominante das relações internacionais a noção de que os governos nacionais orientam seu agir essencialmente a fins e não com base em princípios morais. O texto destaca as razões que falam a favor de uma maior consideração da dimensão do reconhecimento na explicação das relações internacionais e explora as implicações normativas que surgem a partir de tal mudança de paradigma para a compreensão e o tratamento das relações internacionais. Narrativas justificadoras da ação política recebem aqui um papel destacado.

Palavras-chave: Reconhecimento político; Relações internacionais; Identidade coletiva; Conflitos internacionais; Narrativas justificadoras da ação política

Abstract: Contrary to the everyday perception that the state actors aim with their actions on the respect and recognition of the community they represent, prevails in the dominant modern theory of international relations the notion that national governments essentially act purposive-rationally and not based on moral principles. The text highlights the reasons that speak for a stronger consideration of the dimension of recognition in explanations of international relations and explores the normative implications that arise from such a paradigmatic shift for the understanding and explanation of international relations. Narratives of justification of political action will have a central role in this context.

Keywords: Political recognition; International Relations; Collective identity; International conflicts, Narratives of justification of political action

\footnotetext{
* Doutor e livre-docente em Filosofia, professor na Universidade de Frankfurt, Alemanha, e diretor do Instituto para Pesquisa Social. Principais publicações: Luta por reconhecimento (Editora 34), Verdinglichung (Suhrkamp), Sofrimento de indeterminação (Esfera Pública). $<$ honneth@em.uni-frankfurt.de>. Este texto (Conferência apresentada no $4^{\circ}$ Simpósio Internacional sobre a Justiça. Porto Alegre, 29 set.- $1^{\circ}$ out. 2009), ainda inédito, foi gentilmente cedido para publicação na Civitas pelo autor e pela Editora Suhrkamp. Tradução do alemão: Emil A. Sobottka e Joana Cavedon Ripoll.
}

\begin{tabular}{|l|l|l|l|l|l|}
\hline Civitas & Porto Alegre & v. 10 & n. 1 & p. $134-152$ & jan.-abr. 2010 \\
\hline
\end{tabular}


Num nível pré-teórico parece que pressupomos como óbvio que a conduta e o agir dos atores estatais perante outros estados sejam frequentemente movidos pela intenção de pressionar para que eles respeitem a coletividade por eles representada e a intenção de exigir o reconhecimento com medidas correspondentes para tanto. Assim, na troca cotidiana de opiniões, rapidamente concordamos que o comportamento das lideranças políticas da Palestina não seja compreensível sem levar em consideração tal aspiração por reconhecimento, que o governo da Rússia já há anos faz dispendiosas ações para alcançar uma consideração maior por parte dos estados ocidentais ou que os governos dos países da Europa Ocidental, por meio de relações diplomáticas e subterfúgios, desejavam adquirir novamente respeito frente à administração Bush (Wolf, 2008). Com certeza, num primeiro momento não haverá surpresa alguma com essa aplicação da categoria do reconhecimento às relações internacionais entre estados; afinal, o mais recente resgate da teoria do reconhecimento de Hegel também estava motivado pela intenção de dar novamente uma linguagem mais fortemente teórico-moral ao comportamento de atores coletivos e de grupos sociais, e assim retirá-lo do paradigma predominante puramente estratégico, racional voltado a fins (Honneth, 2003b, cap. 8).

Mas já o velho Hegel, em sua Filosofia do Direito, havia negado a possibilidade de uma aplicação da ideia de uma "luta por reconhecimento" ao nível do agir entre estados, pelo menos para as "nações civilizadas", ao tentar descrever a relação dessas entre si segundo o modelo de uma autoafirmação do estado nacional, dentro do marco do direito internacional ${ }^{1 \mathrm{~N} . t}$. amplamente aceito. Uma busca por reconhecimento e respeito de um único estado ele só queria admitir para povos subdesenvolvidos, sem lei, que ele via historicamente lutar em vão por sua honra e prestígio enquanto, segundo sua visão, os estados de direito esclarecidos do Ocidente perseguiam unicamente os seus objetivos de maximização do bem-estar e de manutenção da segurança, definidos nacionalmente (Hegel, 1970, § 338-352). É esta imagem que também a teoria oficial das relações internacionais assumiu para si nos últimos anos. Sem recorrer a Hegel, está vigente a concepção de que, a partir do momento de sua declaração de independência nos termos do direito internacional, governos estatais se orientam essencialmente pelo objetivo de autoafirmação do estado nacional, e, por conseguinte, são bastante insensíveis a questões relativas ao respeito entre estados e às relações de reconhecimento. Nesse sentido, parece haver entre nossas situações cotidianas e as teorias predominantes um

N.t. A tradição alemã utiliza Völkerrecht e seus derivados a partir do latim ius gentium ou jus gentium, aqui traduzido como direito internacional. 
abismo nada desprezível e difícil de ser transposto: enquanto aceitamos aqui a interpretação do agir estatal exclusivamente segundo o modelo da perseguição racional dos interesses, ao interpretarmos o comportamento estatal nas situações cotidianas com frequência levamos em consideração motivos quase morais da busca por reconhecimento e da violação do respeito.

Contudo, as opiniões pré-teóricas em geral não subsistem por muito tempo diante de modelos científicos. A concepção segundo a qual atores e governos estatais perseguem exclusivamente interesses da autoafirmação coletiva possui tal força sugestiva que nós, após renovada avaliação, logo deixamos para trás nossas intuições cotidianas e aderimos ao esquema padrão da orientação exclusivamente utilitária; nessa perspectiva, aquilo que antes era tido quase naturalmente como um ato estatal de respeito violado ou da busca por reconhecimento se apresenta novamente apenas como um agir simbolicamente oculto motivado por considerações relativas aos interesses do estado nacional. A questão levantada pela tensão assim esboçada é inicialmente de natureza puramente empírica, descritiva: o modelo conceitual oficial do ator racional orientado a fins serve efetivamente para explicar todas as tensões políticas, conflitos e guerras em que hoje os diversos estados do mundo estão envolvidos entre si em diversos lugares? Formulado a partir da outra perspectiva, a das nossas situações cotidianas, a pergunta deveria ser se não seria necessário levar em consideração também motivos primários da busca por reconhecimento e da conquista de respeito para explicar a conduta conflitiva e a política externa de atores estatais. Obviamente que com a resposta a essas perguntas também estão relacionadas de modo opaco consequências normativas, que não podem ser de todo desconsideradas pois, quanto mais destacarmos as buscas dos estados individuais por reconhecimento em nossa interpretação das relações internacionais, tanto mais cedo aparentemente necessitamos admitir que esses não se comportam de forma independente das reações políticas de suas contrapartes, e com isso estão cientes, do modo latente, da necessidade de assentimento internacional de sua identidade coletiva. Mesmo que desta mudança de perspectiva não possam resultar indicações diretas para a ação, através dela provavelmente se delinearia um forte apelo em favor da ideia de, nos conflitos internacionais, apostar antes na "força suave" do que na "militar" ou na "força bruta". ${ }^{2}$ Por conseguinte, a escolha do marco interpretativo para o agir estatal não deixa de ter consequências para a resposta à pergunta normativa sobre como os estados deveriam relacionar-se uns com os outros futuramente em casos de tensões, disputas ou conflitos; dependendo

\footnotetext{
2 Sobre essas categorias, veja Nye (2004).
} 
do caso, se destacamos antes o aspecto da autoafirmação do estado individual ou aquele da política externa em busca de reconhecimento, mudará também nosso horizonte conceitual normativo com vistas à estruturação das relações internacionais.

A seguir tentarei responder as questões que acabo de esboçar. Num primeiro passo tratarei de elucidar as razões que falam a favor de maior consideração das dimensões do reconhecimento na análise das relações internacionais; trata-se, como mencionado, da pergunta puramente descritiva sobre quais os recursos categoriais adequados para descrever conflitos e tensões entre estados individuais (1). No segundo passo tentarei então indicar as consequências normativas que resultam da mudança de paradigma sugerida para o tratamento das relações internacionais; também aqui, por falta de familiaridade com o tema, deverei contentar-me com reflexões experimentais, mas que a despeito disso devem deixar claro que com o destaque das dimensões do reconhecimento também nosso olhar moral sobre a política mundial mudaria significativamente (2).

A dificuldade central que surge quando se aplica a categoria do reconhecimento ao campo das relações internacionais já se revela na busca de um vocabulário teórico adequado; tão logo tentamos enumerar as dimensões do respeito no agir estatal, parecem nos estar disponíveis apenas termos que, devido a sua procedência das relações intersubjetivas, possuem um pendão muito forte para o psicológico ou o mental; falamos então, um pouco desajeitados e reticentes, da busca por reconhecimento ou da necessidade de respeito de atores estatais individuais, mesmo sabendo que esses conceitos psicológicos não descrevem adequadamente a situação mencionada. Enquanto transferimos os conceitos da teoria do reconhecimento do plano das relações interpessoais apenas ao comportamento de grupos ou movimentos sociais, não somos confrontados com esse tipo de problemas de natureza terminológica; aqui consideramos a identidade coletiva da respectiva comunidade como o correspondente superior da identidade pessoal ou da autorrelação, de modo que dispomos de uma concepção relativamente clara sobre aquilo que está em disputa nessa luta por reconhecimento que não ocorre entre indivíduos, mas entre grupos. Por isso nunca foi difícil falar de uma "política do reconhecimento" na qual grupos minoritários lutam pelo respeito jurídico ou pela valorização social de sua identidade coletiva; o ponto de partida, nesse caso, está dado pela experiência partilhada da exclusão, da humilhação ou do desrespeito, 
que mobiliza os membros desse grupo a se unirem mais fortemente e a engajarem-se solidariamente em favor do reconhecimento jurídico ou cultural (Taylor et al., 1993, p. 13ss; Habermas, 1996; Honneth, 2003a, espec. p. 191ss).

Quando, porém, passamos do plano dessas lutas de grupos para o plano das relações entre estados, essa transferência torna-se tanto mais difícil quanto mais abrangentes forem os problemas conceituais. Falar de uma identidade coletiva com referência a formações estatais não se tornou impossível apenas desde o momento em que a ficção de uma população nacionalmente homogênea começou a se dissolver definitivamente face à pluralidade dos subgrupos étnicos e culturais; também ali onde por circunstâncias históricas a ideia de um estado-nação (Staatsnation) ainda pode firmar pé, as agências estatais não podem ser vistas como meros órgãos executivos de uma identidade coletiva, pois elas constantemente precisam assumir tarefas autônomas da garantia de segurança, da manutenção do poder e da coordenação econômica. Obviamente que não é só o recorte dessa constelação da responsabilidade estatal que muda segundo a forma da organização política dominante, mas muda também o modo de sua descrição segundo o tipo de teoria estatal utilizada: se como função do estado liberal-democrático for vista principalmente a gestão "biopolítica" da população ou a geração de condições de justiça social compatíveis com a segurança, isso tem como consequência uma grande diferença no modo como as tarefas dos atores estatais serão descritas em sua especificidade. Mas também, para além dessas diferenças nas formas do estado e nos sistemas teóricos de descrição, permanece válido que mesmo em suas funções de política externa os órgãos estatais não podem simplesmente ser concebidos como instâncias complacentes de articulação de uma identidade coletiva; ao contrário, eles estão sujeitos a constrangimentos e imperativos que resultam da tarefa de assegurar externamente os limites territoriais, o bem-estar econômico e a segurança política do próprio país. Nesse sentido, não é possível simplesmente proceder a uma transferência das categorias do reconhecimento segundo o princípio de que em todo lugar em que existir uma identidade coletiva também deve haver o comportamento correspondente de uma luta por reconhecimento; entre a suposta necessidade de uma população de ser respeitada desde fora em sua própria "identidade", de algum modo abalada, e o comportamento dos atores estatais sempre se interpõem primeiro os teimosos imperativos funcionais da condução política e da manutenção do poder. Os conceitos psicológicos que empregamos quando falamos de "aspirações", "necessidades" ou "percepções" por conseguinte estão deslocados no campo das relações internacionais; atores estatais não são portadores de 
posturas mentais, mas são instâncias de consecução de tarefas politicamente estabelecidas.

No entanto, já existe no nível da linguagem teórica um conceito do "reconhecimento" que é utilizado com naturalidade no âmbito das relações internacionais. Pelos estatutos do direito internacional, um ente coletivo organizado politicamente só recebe o direito a uma existência legal se outros estados, por sua vez já reconhecidos nos termos do direito internacional, o "reconhecem" legalmente como um "estado"; entre as tarefas que um governo pode assumir na política externa está, portanto, a de examinar se uma determinada comunidade, que já se entende como organizada em forma de estado, efetivamente cumpre já as condições gerais definidas para a existência de um "estado" (Kelsen, 1941). Segundo Hans Kelsen, esse ato estatal do reconhecimento jurídico necessariamente deve ser compreendido como um acontecimento recíproco, porquanto o novo estado recém reconhecido só pode tornar-se de modo vinculante um sujeito de pleno direito do estado-nação se, em sentido oposto, também ele tributa reconhecimento nos termos do direito internacional ao estado que o reconhece; enquanto esta ação subsequente não for efetivada, o nascimento de um novo estado nos termos do direito internacional em certo sentido ainda estará incompleto, porque ele ainda não colocou à prova sua competência como um membro da comunidade jurídica dos estados (ibid., p. 609).

Evidentemente que Kelsen nesse contexto também realça claramente que estes atos estatais do reconhecimento só têm o significado de uma constatação de situações empíricas e não o caráter de alguma manifestação de respeito. Se um estado reconhece um ente político coletivo no sentido do direito internacional, então isso não significa outra coisa do que ele considerar que nesse caso estejam dadas as condições para a existência como estado; não se trata, portanto, da manifestação de uma intenção normativa, mas tão somente da simples tomada de conhecimento de um fato: "o ato legal do reconhecimento é o estabelecimento de um fato; não é a expressão de uma vontade. Ele é conhecimento antes que re-conhecimento" (ibid., p. 608). Para poder efetivamente falar do "reconhecimento" estatal de um outro estado segundo Kelsen, portanto, deveria haver uma certa margem para decisão. Não deveriam ser unicamente constatadas situações de fato para, a partir delas, possivelmente tirar as conclusões necessárias de um reconhecimento jurídico, mas deveriam ser tomadas decisões sobre se com um outro estado deveria ser assumido um determinado tipo de contato mais intensivo, benévolo. Só nesse segundo nível, como o vê Kelsen, podemos efetivamente falar de um ato normativo do reconhecimento entre estados; pois nesse caso não estamos 
mais diante da consequência necessária de um fato a respeito do qual o estado tomou conhecimento, mas diante da livre decisão de um governo de estado de estabelecer com outro estado uma relação positiva, afirmativa. Para realçar a diferença, Kelsen denomina os comportamentos estatais desse tipo como sendo atos "políticos" do reconhecimento; eles consistem em manifestações da intenção de um governo ou de atores estatais de tratarem o outro estado de agora em diante como um membro da comunidade internacional em igualdade de direito. Mesmo que Kelsen aqui pense principalmente no estabelecimento de relações diplomáticas e em acordos comerciais, sua sugestão conceitual nos dá uma chave para seguir perseguindo no plano teórico as intuições mencionadas no início; pois manifestamente aquilo que temos em mente quando falamos de relações de reconhecimento entre estados, de respeito violado e humilhações, se move precisamente nesse plano que Kelsen tem em mente quando ele fala de atos "políticos" do reconhecimento. ${ }^{3}$

Um primeiro passo a ser dado para circunscrever melhor esse plano consiste no destaque da base de legitimação à qual necessariamente está vinculado todo o comportamento de atores estatais. Esses atores não podem cumprir a função a eles atribuída, de autoafirmação do estado através da política externa, sem levar permanentemente em consideração se o modo de cumprimento dessa função está em consonância com as prováveis expectativas da população; o modo como a segurança política, o volume de poder e o bem-estar econômico do respectivo estado são protegidos em relação ao exterior precisa ser submetido à esperada concordância dos afetados já devido à demonstração de sua capacidade funcional. Essa vinculação do agir em termos de política externa à legitimação também é importante lá onde não se trata de sistemas políticos de recorte democrático; pois também nesses países governados de forma autoritária ou ditatorial, como é o caso hoje do Irã e da República Popular da China, por exemplo, os detentores do poder e as elites geralmente estão conscientes de que seu poder delegado de ação só se sustenta na proporção da concordância pública com suas ações. E da população de um ente estatal se supõe que, para além da diferenciação cultural, étnica ou religiosa interna, ela tenha vivo interesse em ver seu próprio país sendo adequadamente respeitado e valorizado por parte dos outros estados: aquilo que perfaz o autorrespeito de uma coletividade organizada como estado, as provas de afirmação do passado, a força de resistência contra tendências autoritárias, as realizações da própria cultura, tudo isso deve ser "reconhecido" pelos representantes políticos dos outros povos (Rawls, 2002, p. 38s). Nesse ponto não se pode cometer o equívoco de equiparar esse tipo de

\footnotetext{
3 Para uma perspectiva dessas nas relações internacionais, ver Wolf (2008) e Haake (2005).
} 
interesses imediatamente com convicções nacionalistas ou até mesmo com a concepção de supremacia do próprio povo; não apenas porque hoje a identidade coletiva de uma população organizada em estado dificilmente pode se apoiar ainda em características comuns pré-políticas ou étnicas, não apenas porque os processos de globalização cultural contrariam todas as intenções de uma glorificação da própria cultura nacional, ${ }^{4}$ mas sobretudo porque o desejo de um reconhecimento internacional de tudo aquilo que perfaz em cada caso o autorrespeito coletivo volta-se fundamentalmente à inclusão e não à exclusão dos outros estados. Exemplos sutis para essas aspirações podem ser encontrados no frequentemente irritante entusiasmo que pode cativar toda uma população quando sua equipe venceu numa competição esportiva internacional; ou no orgulho ingênuo com que os habitantes de um país chamam a atenção do visitante para os feitos culturais que coroam o passado da própria coletividade. Tudo isso não é nem nacionalismo e, naturalmente, também ainda não patriotismo constitucional - aquele não, porque falta o recurso à figura de um inimigo, com efeito duradouro; esse não, porque não precisa tratar-se necessariamente de uma postura afirmativa em relação a sua própria constituição democrática. $\mathrm{O}$ que se busca é, ao contrário, uma forma de reconhecimento coletivo sem o qual a própria identidade coletiva não pode ser mantida inequívoca e inabalada.

É esse tipo de expectativa coletiva de uma população a que geralmente os atores políticos de um ente estatal precisam sentir-se vinculados em suas atividades de política externa; por razões relativas à legitimação de seu próprio agir eles, no cumprimento de suas tarefas funcionalmente definidas, se veem compelidos a expor condignamente os traços dignos de reconhecimento do país por eles representados. Nesse sentido, a busca coletiva por reconhecimento não integra o horizonte de tarefas do agir estatal como uma função específica; ela antes dá um colorido e um toque de fundo ao modo como são cumpridas pelos atores políticos as tarefas a eles atribuídas constitucionalmente.

Para tornar claro diante de que possibilidades alternativas os atores estatais ou governos se encontram aqui é obviamente necessário dar um segundo passo na análise; faz-se necessária uma conscientização resoluta do horizonte simbólico de significado em que todo comportamento das instâncias estatais necessariamente está inserido. As medidas e ações dos atores políticos têm, para além de seu conteúdo explicitamente formulado, uma série de outros significados importantes que são transmitidos através do modo de sua encenação simbólica: a utilização de determinadas metáforas, publicamente fáceis de serem decifradas, o uso de rituais historicamente habitualizados, e até mesmo

\footnotetext{
4 Sobre essas tendências, ver Habermas (1987).
} 
a condução consciente da mímica e dos gestos nos eventos políticos - tudo isso pertence ao amplo leque de meios simbólicos com auxílio dos quais os atores estatais podem transmitir de modo proposital mensagens que ultrapassam o conteúdo "oficial" de seus comunicados. ${ }^{5}$ Pode-se suspeitar que muito daquilo que Kelsen designou como sendo "reconhecimento político" entre estados transcorra nessa forma de uma encenação simbólica do comportamento na política externa: as expressões com as quais se pretende chamar a atenção para a identidade coletiva do próprio país ou a consideração que se quer demonstrar pelas realizações da população de um outro país via de regra não fazem parte do conteúdo explícito das respectivas transações, comunicado explicitamente, mas estão contidos no modo de sua encenação simbólica. Naturalmente há sempre de novo também situações em que representantes de um governo imaginam estar agindo de acordo com a opinião política em seu país quando expressam diretamente um certo reconhecimento da cultura de uma outra população. Um exemplo marcante para esse tipo de manifestação explícita de respeito certamente é o admirável discurso que o presidente norte-americano Obama deu na universidade do Cairo diante de um grande número de representantes políticos e espirituais do mundo islâmico: desde a saudação feita em árabe até as repetidas menções às realizações do islã, nesse discurso tudo estava orientado a neutralizar a impressão do desprezo que pode ter surgido em muitos países árabes durante os anos da administração Bush (Obama, 2009). Muito mais difícil, no entanto, é encontrar situações em que de parte dos atores políticos seja exigido explicitamente respeito pela identidade coletiva da própria população; a manutenção da aparência da independência do estado-nação da consideração por outros países, o objetivo de não desnudar-se publicamente, a etiqueta dos encontros diplomáticos, tudo isso evitará que o desejo de um povo de ter sua identidade coletiva reconhecida seja expresso direta e publicamente pelos seus representantes na política externa. Por conseguinte, uma articulação de modo unicamente indireto e simbólico é típica para essa dimensão do reconhecimento em relações internacionais: um comportamento que externamente serve apenas para a manifestação de interesses estatais de autoafirmação é encenado simbolicamente de tal modo que represente um jogo implícito e bem calculado de manifestação de respeito e desprezo, de desejos de reconhecimento e experiências de humilhação.

Nesse sentido também é problemático distinguir no comportamento de política externa de um estado uma dimensão estratégica da autoafirmação de uma dimensão do reconhecimento. Atores políticos nas transações com

\footnotetext{
Sobre isso ainda ver Edelman (1976); uma crítica se encontra em Honneth e Paris (1979).
} 
outros estados não perseguem primeiro tão só os interesses racionais voltados à garantia do poder e à maximização do bem-estar, para depois, numa espécie de apêndice ainda adicionalmente prestar ou retratar reconhecimento político; ao contrário, eles sempre definem já os interesses dentro do horizonte da expectativas normativas, que eles presumem na própria população como sendo desejos difusos de reconhecimento da identidade coletiva própria ou alheia. Portanto é falso o pressuposto teórico de uma camada primária, distinta, de intenções ou cálculos puramente estratégicos; atores estatais nem conseguirão formular esses interesses independentemente de considerações sobre quais necessidades de reconhecimento eles pressupõem na frágil coletividade da própria população e quais desejos de reparação moral eles pressupõem na coletividade igualmente porosa da população alheia. Pelo fato de que os representantes políticos, por causa da busca por legitimidade, precisam agir sempre como intérpretes das experiências e desejos de sua própria população, todos os encontros e relações entre estados já ocorrem sob a pressão moral de um conflito por reconhecimento: questões desse tipo - a necessidade de uma autoimagem na esfera pública mundial, o afastamento de uma vergonha ou humilhação, o desejo de reparar uma injustiça estatal - determinam a perseguição dos interesses na política externa de tal modo, que deles não podem mais ser analiticamente separados.

Tudo isso, como já foi mencionado, se refere obviamente só ao nível descritivo da análise das relações internacionais. Quando se tratar de explicar a relação entre estados, então faz pouco sentido pressupor primeiro um feixe apenas de constelações de interesses referidos à autoafirmação estatal, para então adicionar uma "necessidade" de reconhecimento difícil de localizar; os atores estatais, ao contrário, já definem sempre aquilo que lhes parece necessário para garantir a existência do país por eles representado à luz de interpretações que eles fazem dos desejos de reconhecimento coletivo existentes na própria população. Naturalmente os respectivos detentores do poder ou representantes políticos sempre dispõem de um certo espaço de flexibilidade para interpretar as percepções difusas e desordenadas crescentes em meio à população em uma ou outra direção - a saber, para colocar em relevo as tendências conciliatórias ou as mais hostis; só naqueles estados democráticos de direito nos quais a própria constituição procede a uma interpretação da identidade nacional-estatal orientada por princípios eles estão subordinados a determinadas diretrizes na realização de tais aspirações coletivas por reconhecimento. Mas em nenhum ente estatal os atores políticos podem simplesmente ignorar as demandas da identidade coletiva de sua população, porque do contrário eles colocariam em risco os necessários vínculos de lealdade; por isso na interpretação e na 
realização das funções a eles atribuídas eles sempre necessitam levar em consideração quais as expectativas que os membros de seu ente coletivo cultivam em relação ao comportamento de outros estados. Aqueles autores que, como Hegel, se recusam amplamente a aceitar para o caso de estados civilizados semelhante vínculo entre comportamento em política externa e aspirações coletivas de identidade, desconhecem a profundidade do significado do elo mediador da garantia de legitimidade do agir político; na explicação das relações internacionais eles julgam poder prescindir da atenção às demandas morais das identidades coletivas porque não querem admitir que também os entes estatais modernos, funcionalmente diferenciados, dependem do consentimento de seus membros.

Quando tentamos encontrar exemplos no passado recente que tornem essa tese plausível, então encontramos uma multiplicidade de casos, tanto em sentido positivo como negativo. No polo negativo certamente encontra-se a política de conquista territorial da ditadura nacional-socialista, que não pode ser explicada sem as percepções de vergonha disseminadas numa ampla parte de população alemã devido aos tratados de Versalhes, que eram eficazes até mesmo na percepção política de um inimigo externo; nesse ponto, é quase impossível analisar o comportamento do governo nacional-socialista na política externa independentemente da tentativa bem-sucedida de focalizar aqueles sentimentos difusos naquele único tema de uma humilhação nacional por "Versalhes" de tal maneira, que dali foi possível derivar a justificação para uma política agressiva da reparação e da vingança (Cohrs, 2006). ${ }^{6}$ No polo contrário, positivo, do passado recente provavelmente estejam as aspirações de reconciliação na política externa do novo presidente norte-americano, que não seriam adequadamente explicáveis se nelas não fosse vista também uma tentativa de superação de um sentimento amplamente disperso da vergonha isolante na própria população. Por certo que em ambos os casos se trata de casos extremos de uma luta por reconhecimento politicamente mediatizada: no primeiro caso, os detentores políticos do poder transformam um sentimento difuso existente na população em uma narrativa justificadora que os permitiu levar a cabo uma campanha militar de conquista e vingança; no segundo caso, um presidente democraticamente eleito, graças a seus grandes dons retóricos, consegue interpretar um mal-estar paralisante da maioria da população em tal sentido, que ele lhe forneça a justificação para gestos conciliatórios frente a estados até então inimigos. Mas os dois exemplos revelam, de modo distinto, que a determinação dos objetivos da política externa não pode ser separada das

\footnotetext{
Agradeço a Volker Heine pela referência..
} 
reivindicações da identidade coletiva pressupostas em cada caso; nem da forma como estados reagem uns em relação aos outros e de quais os tipos de relações que mantêm entre si. Isso é matéria de uma fusão de interesses e valores levada a efeito em ambos os lados, ou seja, da respectiva descoberta de objetivos da política externa a partir da perspectiva do hipotético "nós" de uma população que é interpretada como uma coletividade em busca de reconhecimento. A terminologia psicológica, da qual no início foi dito que deveria ser evitada na interpretação de relações internacionais, acaba encontrando aqui ainda um lugar - contudo, não como parte da linguagem teórica em si, mas como um de seus objetos na realidade política na qual atores estatais necessitam dar forma às tendências da opinião encontradas na população com a ajuda de conceitos da busca por reconhecimento e da humilhação histórica.

O espectro moral dos exemplos recém mencionados obviamente também revela em quantas direções a mobilização política dessas percepções coletivas podem indicar: o interesse adscrito a uma população, de receber de outros povos a estima devida e o reconhecimento correspondente para sua identidade coletiva, pode ser manifestamente instrumentalizado para a legitimação tanto de uma política agressiva de conquista como também para uma política conciliatória de distensão. Com isso são abordadas questões que não dizem mais respeito ao lado descritivo, mas ao lado normativo de uma teoria das relações exteriores.

\section{2}

O tipo de reconhecimento que desempenha um papel constitutivo na interpretação da dinâmica das relações internacionais, segundo minha convicção, não pode mais ser dividido em subtipos. Diferente de grupos ou movimentos sociais, nos quais podemos determinar o tipo específico do reconhecimento coletivo almejado com base nas próprias manifestações dos participantes e protagonistas, povos organizados em forma estatal constituem uma figuração muito amorfa para que se possa proceder a uma diferenciação empírica semelhante; por conseguinte, precisamos contentar-nos aqui com o suposto relativamente vago de que os membros de um ente coletivo estatal em geral têm um interesse difuso em serem respeitados por parte de outros estados no seu autorrespeito partilhado coletivamente e em receberem deles reconhecimento por sua história e cultura comuns.

Outras diferenciações similares às que são possíveis entre os diferentes modos do reconhecimento como resultado de relações intersubjetivas (Honneth, 2003b, cap. 5) parecem fazer pouco sentido no nível altamente agregado de populações inteiras; se elas almejam por sinais de boa vontade, 
por equiparação jurídica ou por estima social de parte do outro lado, tudo isso é praticamente impossível determinar porque os motivos dos membros são muito diferenciados, suas intenções muito difusas e seus objetivos pouco integrados. ${ }^{7} \mathrm{Na}$ análise da relação entre estados, essas diferenciações adicionais de qualquer modo desempenham apenas um papel muito secundário; pois decisivo nelas não é o tipo de reconhecimento que determinada população "efetivamente" almeja, mas aquilo que os atores políticos e detentores do poder fazem interpretativamente em cada caso com as tendências perceptivas correspondentes. O "nós" da população, que sempre precisa ser acolhido na determinação dos objetivos da política externa, não é uma grandeza empírica, mas hipotética; ele surge quando das expectativas e percepções desordenadas, apenas supostas, é formada uma narrativa coletiva que permite uma espécie determinada da relação entre estados parecer como justificada à luz de humilhações experimentadas ou reconhecimento almejado. ${ }^{8}$

Essas narrativas justificadoras são a chave para as questões normativas que se colocam hoje no entorno da formação das relações internacionais. ${ }^{9} \mathrm{De}$ sua constituição dependem sucesso ou fracasso das chances para modificar as relações entre estados numa direção que permita que uma desconstrução de disputas bélicas e um aumento da cooperação pacífica pareçam mais promissoras. Tão logo nos afastamos dos problemas descritivos de uma teoria das relações internacionais e nos voltamos para seus problemas normativos, assumimos outra perspectiva frente às relações conflitivas de fato existentes no mundo que não a tentativa de sua explicação empírica; não perguntamos mais como podemos descrever adequadamente esses conflitos dos estados, mas quais as condições que deveríamos criar e quais medidas tomar para torná-los menos prováveis, a fim de que no conjunto uma situação mais predisposta à paz possa ser esperada nas relações internacionais. No entanto, as questões do segundo tipo não são passíveis de resposta totalmente independente das do primeiro tipo na medida em que uma explicação adequada sobre as causas do comportamento conflitivo do estado nos informa quais soluções deveríamos divisar para a superação das condições dadas. O "realismo" de nossas reflexões normativas e utopias (Rawls, 2002, § 1) cresce na medida em que dispomos de hipóteses acertadas a respeito das ponderações sobre as quais atores estatais e governos planejam e calculam suas relações com outros estados. Nessa interface entre facticidade empírica e reflexões normativas, aqueles pressupostos teóricos

\footnotetext{
7 Nesse sentido tenho reservas contra a sugestão feita por Erik Ringmar em seu texto introdutório ao livro The international politics of recognition (no prelo), de resto muito digno de análise.

Sobre o mecanismo desse tipo de "construção", cf. Anderson (1988).

9 Sobre o conceito das "narrativas justificadoras", cf. Forst e Günther (2009, p. 23-27).
} 
desenvolvidos na primeira parte do texto desempenham um papel central; pois se for procedente que os estados somente podem determinar o tipo de suas relações externas mediante a consideração das narrativas justificadoras que, na perspectiva dos membros da sociedade, devem conter uma interpretação fidedigna e convincente de seus interesses por autorrespeito coletivo, então por esta via indireta as relações "políticas" de reconhecimento no nível internacional adquirem uma importância decisiva nas medidas destinadas à desconstrução de conflitos entre estados.

A ideia normativa básica que se pretende referir com isso resulta da estreita vinculação existente em cada caso entre a matéria prima das percepções coletivas e as narrativas justificadoras estatais. Tal como mencionado acima, os atores estatais só podem descobrir e determinar os objetivos de seu comportamento político externo ao considerarem os interesses elementares de segurança e bem-estar à luz de interpretações nas quais eles sintetizaram narrativamente as expectativas difusas da população; nisso lhes são colocados limites muito estreitos, porquanto as construções sintetizadoras das percepções coletivas sempre precisam revelar-se eficazes para fornecer uma explicação sofrivelmente adequada e convincente das efetivas mas difusas expectativas assumidas. Narrativas justificadoras desenvolvidas para fundamentar a perseguição hostil e agressiva de interesses da política externa só permanecem intactas enquanto a população do respectivo país também tiver motivos perceptíveis para se ver diminuída em seu coletivo autorrespeito pelo comportamento dos outros estados; se esses pretextos deixam de existir, sentimentos de humilhação e diminuição não podem mais alastrar-se na dispersas esferas públicas dos cidadãos, e assim também a narrativa justificadora perde em credibilidade rapidamente e não pode mais desempenhar seu papel legitimador. Isso que aqui é referido para a situação negativa de uma política externa agressiva, naturalmente também vale em sentido contrário para uma política externa conciliadora, disposta a cooperar. Uma interpretação narrativa que sustenta este tipo de comportamento de atores estatais só pode ser mantida enquanto nos fóruns da formação pública de opinião e tendências não prevalecer a percepção de ser diminuído pelo outro lado nas condições do próprio autorrespeito. Em ambos os casos, a sensibilidade coletiva de uma população que acompanha com interesse e suspeita os sinais da conduta de reconhecimento de outros estados se revela como o gradiente decisivo no desempenho das narrativas justificadoras da política externa: quanto maior se tornar a distância que se abre entre as tendências difusas no povo do estado e as justificativas públicas do comportamento político, tanto mais cedo os atores estatais encontrarão dificuldade para sustentar sua própria interpretação dos objetivos de política externa do país por eles representado. Nesse sentido, 
assim se poderia dizer, estados podem influenciar de modo indireto nas decisões relativas ao comportamento em política externa de outros entes estatais; pois através dos meios simbólicos de suas manifestações externas sobre respeito e reconhecimento eles dispõem de um instrumento com o qual podem influenciar a formação pública de opinião e tendências no outro país.

Com esse resultado intermediário já se conquistou mais do que parece transparecer num primeiro olhar para as questões normativas que perseguimos. Já havíamos visto que todo comportamento de um estado em política externa advém de uma liga específica de interesses e valores; nela as exigências funcionais da maximização de segurança e bem-estar devem tornar-se coincidentes com aquelas expectativas públicas que a respectiva população nutre frente aos outros estados com relação ao reconhecimento de sua identidade coletiva. Para esta finalidade, atores estatais ou governos precisam basear-se em narrativas justificadoras que têm por finalidade fundamentar, à luz de acontecimentos e episódios históricos, por que os interesses do próprio país devem ser perseguidos de uma determinada maneira, seja ela cooperativa ou agressiva. Mas nós já vimos também que outros estados podem exercer influência indireta sobre essas legitimações do comportamento em política externa na medida em que eles conseguem influir na formação de opinião e tendências da respectiva população a partir de fora; porquanto através dos multifacetários instrumentos de uma sinalização de reconhecimento ou humilhação é-lhes dado um meio para colocar em dúvida a narrativa justificadora do outro lado ao demonstrar uma visão dela dissonante sobre a identidade coletiva da outra população. Esse tipo de medida cria em certo sentido uma fissura entre as autojustificações dos atores estatais e a formação pública de opinião entre a população; elas tentam influenciá-las por meio de manifestações críveis de respeito e reconhecimento no sentido de não mais dar crédito àquelas narrativas justificadoras. Ainda que a história política das relações internacionais esteja repleta deste tipo de iniciativas, elas só têm um papel menor na respectiva teoria; pelo fato de que o agir estatal é interpretado sobretudo segundo o modelo da perseguição racional de interesses. Falta um marco conceitual que pudesse dar à dinâmica afetiva das relações de reconhecimento entre estados um lugar adequado. No plano normativo da teoria, essa exclusão se vinga na falta de criatividade procedimental com a qual chances para a diminuição de disputas hostis e para a construção de cooperações pacíficas pudessem ser refletidas; no essencial são visadas aqui medidas do equilíbrio de interesses ou de acordos internacionais, mesmo que a história dos conflitos nos ensine que as percepções coletivas de reconhecimento e humilhação por outros estados desempenham um papel incomparavelmente maior. 
A via pela qual, por conseguinte, seja mais provável a possibilidade de ampliar as chances de civilização das relações internacionais consiste antes de mais nada na manifestação duradoura de respeito e da estima social para a identidade coletiva da população do outro país. Antes que convenções jurídicas possam desempenhar sua obra pacificadora, antes ainda que o cultivo de relações diplomáticas e acordos comerciais possam realizar a desconstrução de tensões, são sempre necessários primeiro sinais publicamente visíveis de que a história e a cultura do povo do estado em questão merecem ser percebidos na balbúrdia dos povos; somente através de semelhante reconhecimento, transmitido por sobre as cabeças dos representantes governamentais e dos atores políticos, é possível assegurar que as cidadãs e os cidadãos do outro estado não darão mais crédito às imagens oficiais de inimigo criadas por suas elites, que eles portanto podem adquirir a confiança de serem levados a sério pelos seus contrapartes. A história das relações internacionais contém exemplos suficientes que mostram que um atropelo desse princípio básico só faz aumentar o perigo dos conflitos entre estados e que seu respeito já diminuiu o potencial destas cisões; o ato de Willi Brandt, de ajoelhar-se em Varsóvia, foi um gesto internacionalmente perceptível que durante anos tornou quase impossível ao governo polonês a nova evocação de preconceitos e ressentimentos contra a República Federal da Alemanha antes existentes na própria população (Schneider, 2006); o proposital esquecimento europeu e sobretudo alemão da luta sofrida e cheia de privações da população sérvia contra a ditadura nacional-socialista abriu o caminho para aquela política fatal de um reconhecimento internacional precipitado de alguns entes estatais da ex-Iugoslávia (Côsovo, Croácia) que empurrou o governo da Sérvia cada vez mais ao isolamento e com isso ao fim e ao cabo deu suporte a suas narrativas justificadoras ultranacionalistas na esfera pública local; ${ }^{10}$ a participação insuficiente dos estados internacionalmente líderes na situação existencial humilhante da população na Palestina, sim, a falta de qualquer manifestação cabível de solidariedade, tem como efeito até hoje o fato de que as fantasias cultivadas pelas lideranças locais sobre uma campanha de vingança dirigida contra Israel encontrem sempre de novo disposição coletiva de seguidores também nas camadas mais baixas e empobrecidas do país (Sarraj, 2002). ${ }^{11}$

A lista destes exemplos poderia ser ampliada sem grande dificuldade com uma multiplicidade de casos; pensemos na constante afluência de novos membros com a qual as organizações terroristas islâmicas podem contar há

\footnotetext{
${ }^{10}$ Nisso, a saber, na crítica ao desrespeito da Europa Ocidental pela história repleta de sofrimento da população sérvia, está o lado correto do posicionamento de Peter Handke, a despeito de toda idiosincrasia e dos exageros.

${ }^{11}$ Agradeço a José Brunner pela referência.
} 
anos em suas respectivas áreas de atuação para perceber a dimensão das consequências de uma política internacional equivocada que deveria ter tornado claro o reconhecimento por sobre as instâncias estatais. O primeiro passo para a reconciliação entre estados, para o desenvolvimento de relações pacíficas e cooperativas, sempre consiste no uso do suave recurso de poder que é a manifestação de respeito e estima social, através da qual é sinalizado à população no outro país que em suas realizações culturais ela não está atrás dos demais e que ela pode contar com a participação externa nas suas experiências de sofrimento; quanto mais claras forem essas demonstrações de reconhecimento, quanto mais facilmente elas puderem ser assimiladas nos diversos fóruns da esfera pública da população em questão, tanto antes por sua parte serão colocadas em dúvida construções coletivas que têm por objetivo uma política externa segregacionista e hostil. O melhor meio à disposição dos estados para desarmar, a partir de fora, as imagens hostis e os ressentimentos que grassam em outros entes estatais consiste em sinais mundialmente visíveis e dentro do possível claramente articulados da disposição de incluir a população ali estabelecida na comunidade moral de todos os povos.

Com certeza esses sinais de um reconhecimento não apenas em termos do direito internacional, mas também políticos, não bastam para criar uma base firme para uma relação transnacional de cooperação - a superação intencionada de posturas defensivas alimentadas por experiências coletivas de humilhação, a deslegitimação de imagens hostis surgidas historicamente e atualmente utilizadas como legitimação da dominação precisam ser seguidos por acordos legais que antes do mais assegurem relações pacíficas e que contenham acordos de longo prazo sobre a superação coordenada de desafios comuns. Sobre o fundamento deste tipo de acordos de cooperação, como bem o mostrou o transcurso do processo europeu de unificação desde os Acordos de Roma até a instituição do Parlamento de Estrasburgo (Bach, 2000), podem então surgir redes estáveis de comunidades transnacionais de estados (Brunkhorst, 2005). Mas este tipo de desenvolvimento do descentramento de políticas estatais precisa ser precedido sempre de fases históricas nas quais as populações dos entes estatais envolvidos possam fazer a experiência de que eles se reconhecem reciprocamente nas realizações culturais e nas realizações históricas, que são as respectivas condições para sua autoestima coletiva. Uma teoria política que não tenha conceitos para acessar as raízes afetivas da formação transnacional de confiança também não será capaz de visualizar adequadamente os pressupostos de uma civilização da política mundial. Por isso já é tempo de analisar as relações internacionais sob outro prisma que não aquele em que Hegel e seus seguidores político-realistas o fizeram. 


\section{Referências}

ANDERSON, Benedict. Die Erfindung der Nation: zur Karriere eines folgenreichen Moments. Frankfurt am Main: Campus Verlag, 1988.

BACH, Maurizio (Org.). Die Europäisierung nationaler Gesellschaften. Wiesbaden: Westdeutscher Verlag, 2000.

BRUNKHORST, Hauke. Demokratie in der globalen Rechtsgenossenschaft: einige Überlegungen zur poststaatlichen Verfassung der Weltgesellschaft. Zeitschrift für Soziologie. Sonderheft, 2005. p. 330-348.

COHRS, Patrick. The unfinished peace after World War I: America, Britain and the stabilisation of Europe, 1919-1932. Cambridge: Cambridge University Press, 2006.

EDELMAN, Murray. Politik als Ritual: die symbolische Funktion staatlicher Institutionen und politischen Handelns. Frankfurt am Main: Campus Verlag, 1976.

FORST, Rainer; GÜNTHER, Klaus. Über die Dynamik normativer Konflikte: Jürgen Habermas' Philosophie im Lichte eines aktuellen Forschungsprogramms. Forschung Frankfurt, v. 2, p. 23-27, 2009. Disponível em: <http://www.forschung-frankfurt. uni-frankfurt.de/org/ltg/admin/muk/Publikationen/FFFM/dok/2009_01/2_2009/2_ Rainer_Forst_Klaus_Guenther.pdf $>$. Último acesso: 30 mar. 2010.

HAACKE, Jürgen. The Frankfurt School and international relations: on the centrality of recognition. In: Review of International Studies, v. 31, p. 181-194, 2005.

HABERMAS, Jürgen. Geschichtsbewusstsein und posttraditionale Identität. Die Westorientierung der Bundesrepublik. In: Frankfurt am Main: Suhrkamp, 1987. p. 161-179.

HABERMAS, Jürgen. Kampf um Anerkennung im demokratischen Rechtsstaat. In: . Die Einbeziehung des Anderen. Frankfurt am Main: Suhrkamp, 1996. p. $23 \overline{37-276}$.

HEGEL, G.W. F. Grundlinien der Philosophie des Rechts. Theorie-Werkausgabe. v. 7. Frankfurt am Main: Suhrkamp, 1970.

HONNETH, Axel; PARIS, Rainer. Zur Interaktionsanalyse von Politik. Leviathan, v. 7, n. 1, p. 138-142, 1979.

HONNETH, Axel. Umverteilung als Anerkennung. In: FRASER, Nancy; HONNETH, Axel. Umverteilung oder Anerkennung? Eine politisch-philosophische Kontroverse. Frankfurt am Main: Suhrkamp, 2003a. p. 129-224.

HONNETH, Axel. Kampf um Anerkennung. Zur moralischen Grammatik sozialer Konflikte: mit einem neuen Nachwort. Frankfurt am Main: Suhrkamp, 2003b. Port.: Luta por reconhecimento. São Paulo: Editora 34.

KELSEN, Hans. Recognition in international law: theoretical observations. In: The American Journal of International Law, v. 35, n. 4, p. 605-617, Oct. 1941.

NYE, Joseph S. Soft power: the means to success in world politics. New York: PublicAffairs, 2004. 
OBAMA, Barack, Amerika und der Islam schließen sich nicht aus. Dokumentation der Rede Obamas in Kairo, in: Frankfurter Allgemeine Zeitung, 5. Juni 2009, p. 2.

RAWLS, John. Das Recht der Völker. Berlim: De Gruyter, 2002.

SARRAJ, Eyad El. Dignity, despair and the need for hope. An interview with Eyad El Sarraj. Journal of Palastine Studies, v. 31, n. 4, 2002, p. 71-76.

SCHNEIDER, Christoph. Der Warschauer Kniefall. Konstanz: UVK Verlagsgesellschaft, 2006.

TAYLOR, Charles et al. Multikulturalismus und die Politik der Anerkennung. Frankfurt am Main: Suhrkamp, 1993.

WOLF, Reinhard. Respekt: ein unterschätzter Faktor in den internationalen Beziehungen. Zeitschrift für Internationale Beziehungen, v. 15, n. 1, p. 5-42, 2008. 